\title{
The use of continuous improvement techniques: A survey-based study of current practices
}

\author{
J.V. Kovach ${ }^{1}$, E.A. Cudney ${ }^{2 *}$, C.C. Elrod ${ }^{3}$ \\ ${ }^{1}$ Department of Information and Logistics Technology, University of Houston, USA \\ $2^{2 *}$ Department of Engineering Management and Systems Engineering, Missouri University of Science and Technology, USA \\ ${ }^{3}$ Department of Business and Information Technology, Missouri University of Science and Technology, USA \\ "Corresponding Author: e-mail: cudney@mst.edu, Tel +91-573-3417931, Fax.+91-573-3416567
}

\begin{abstract}
Today, the long-term health of any organization depends on their commitment to continuous improvement. Prior research has focused mainly on the effect of continuous improvement practices on performance. In contrast, this research collected data through a survey administered across multiple industries throughout the U.S. and identified the continuous improvement techniques (i.e., lean and quality improvement methods) that practitioners have successfully implemented within their organizations. It also examined the perceived effectiveness and the challenges/reasons for failure associated with these techniques, as well as determined whether implementation and effectiveness differ between types of operations (i.e., manufacturing versus service). Hence, this research provides a starting point for deploying lean and/or quality initiatives throughout an organization. It also provides guidance for practitioners about what tools are effective in a given situation and what problems they should try to anticipate/overcome when implementing continuous improvement techniques.
\end{abstract}

Keywords: Continuous improvement methods, lean, quality management, Plan-Do-Check-Act (PDCA) cycle, Six Sigma, Toyota Production System (TPS)

DOI: http://dx.doi.org/10.4314/ijest.v3i7.7S

\section{Introduction}

Today, irrespective of the business domain, companies must focus on speed, efficiency, and customer value to be globally competitive, and the long-term health of any organization depends on their commitment to continuous improvement (Juran, 1969; Ishikawa, 1985; Deming, 1986). This type of vision helps companies remain competitive in the face of customers' constantly changing and evolving expectations (Evans and Lindsay, 2005; Sitkin et al, 1994). The principles, practices, and techniques embodied within continuous improvement form a comprehensive organizational philosophy that strives to effectively fulfill customers' needs (Dean and Bowen, 1994), and organizations implement such programs in order to create the knowledge necessary to improve performance (Choo et al, 2007b; Lapré et al., 2000; Mukherjee et al., 1998). Continuous improvement typically involves generating ideas for improvement, testing these ideas, and implementing solutions (Juran, 1974; Gitlow et al, 1995). To support these efforts, there are many techniques (e.g., lean and/or quality improvement methods) from which practitioners can choose to monitor, analyze, and improve work processes, which help to improve both productivity and quality. These techniques help teams effectively use their collective knowledge to develop shared understandings and solve problems (Hackman and Wageman, 1995).

Prior research has focused mainly on the effect of continuous improvement practices on performance (Curkovic et al., 2000; Douglas and Fredendall, 2004; Flynn et al, 1999); yet, such research has shown mixed results. Instead, it may be useful to identify the specific improvement methods that practitioners currently use to improve performance. Previously, Kovach et al. (2008) examined this issue within the healthcare industry. This work found that organizational practices are largely controlled by management functions, which includes the implementation of specific improvement programs and/or techniques. The aim of this research is to obtain a better understanding of the lean and quality improvement methods that practitioners have successfully 
implemented within their organizations. In this study, data about the use of continuous improvement techniques were collected through a web-based survey administered to professionals working in manufacturing and service operations across multiple industries throughout the U.S. In addition to analyzing the successful implementation of these methods, this study also investigates the perceived effectiveness and the challenges/reasons for failure associated with these techniques. In addition, it considers these issues separately for manufacturing and service operations to identify important differences that may exist in certain environments.

The specific objective of this research is to examine the implementation and effectiveness of well-known lean methods as well as the 7 Old and 7 New Tools for quality improvement. The 7 New Tools are referred to as Management Tools as well and were developed mainly to handle "verbal data" as opposed to "hard data" that are handled by the 7 Old Tools. The techniques listed in Table 1 were selected for inclusion in this study based on their widespread use in kaizen, total quality management (TQM), and Lean/Six Sigma projects (Evans and Lindsay, 2005). The research questions investigated in this study include:

1. Which lean methods have the majority of practitioners implemented successfully within their organizations?

a. Does successful implementation differ between types of operations (i.e., manufacturing versus service)?

b. What factors contribute to the successful implementation of these techniques?

2. Which lean methods have the majority of practitioners failed to implement successfully within their organizations?

a. What factors contribute to the failed implementation of these techniques?

3. Which quality improvement methods do the majority of practitioners feel are effective in solving problems within their organizations?

a. Does perceived effectiveness differ between types of operations?

4. What challenges do practitioners face when implementing quality improvement methods?

Table 1. Continuous improvement techniques included in the study.

\begin{tabular}{|c|c|c|}
\hline \multirow{2}{*}{ Lean Methods } & \multicolumn{2}{|l|}{ Quality Tools } \\
\hline & 7 Old Tools & 7 New Tools \\
\hline 1. Value Stream Mapping (VSM) & 1. Flowcharts & 1. Affinity Diagrams \\
\hline 2. 5S/Visual Factory & 2. Check Sheets & 2. Interrelationship Diagraphs (IDs) \\
\hline 3. Standardized Work & 3. Histograms & 3. Tree Diagrams \\
\hline 4. Single Minute Exchange of Die & 4. Pareto Charts & 4. Process Decision Program Charts (PDPCs) \\
\hline (SMED) & 5. Cause and & 5. Matrix Diagrams \\
\hline 5. Poke-Yoke (error-proofing) & Diagrams & 6. Prioritization Matrices \\
\hline 6. Kanban & 6. Scatter Diagrams & 7. Activity Network Diagrams (ANDs) \\
\hline 7. Heijunka (level out the workload) & 7. Control Charts & \\
\hline
\end{tabular}

The empirical nature of this study provides direct insight from practitioners about the use of continuous improvement methods, which furthers our understanding about the improvement techniques used in organizations today. The identification of tools that are more often successfully implemented and perceived to be effective than others provides a starting point for deploying lean and/or quality initiatives throughout an organization. In addition, determining whether the use of these techniques varies between applications in different environments (i.e., manufacturing versus service operations) provides guidance for practitioners about what tools to use in a given situation. Finally, the recognition of causes for why these approaches may fail provides insight for other practitioners about the problems they should try to anticipate/overcome when implementing these techniques. Hence, this research is beneficial for practitioners at various levels, especially those seeking to deploy lean and/or quality improvement methods within their organizations.

\section{Background}

Because continuous improvement methods are based on the need to discover what is not already known, improving system wide performance requires continual learning (Senge, 1992). Knowledge is defined as a true justified belief (Alavi and Leidner, 2001; Nonaka, 1994) that can “enhance an entity's capacity for effective action”' (Sabherwal and Becerra-Fernandez, 2003), and knowledge is created through the process of learning (Vera and Crossan, 2003). The knowledge a company possesses is significant because it varies between organizations and these differences affect relative performance (Kogut and Zander, 1992). The importance of organizational knowledge is supported by the resource-based view of the firm, which suggests how some assets help firms create a sustainable competitive advantage, thus earning superior returns (Peteraf, 1993; Wernerfelt, 1984). Furthermore, the knowledge-based view of the firm supports knowledge as the chief asset of any organization (Grant, 1996; Grant, 1997; Drucker, 1993). In fact, “...the only sustainable advantage a firm has comes from what it collectively knows, how efficiently it uses what it knows, and how readily it acquires and uses new knowledge” (Davenport, 1998). A variety of continuous improvement techniques including both lean and quality improvement methods encourage behaviors that embody learning and result in the creation of knowledge, which organizations need to support productivity and quality improvement efforts. 


\subsection{Lean production}

In 1926, Henry Ford said, "The longer an article is in the process of manufacture and the more it is moved about, the greater its ultimate cost" (Manos et al, 2006). This belief lead Ford to develop the idea of flow production and to be the first to integrate an entire production process (Lean-Enterprise-Institute, 2007). As discussed by Shah and Ward (Shah and Ward, 2007), lean principles originated from Ford's practices, and beginning in 1937, Taiichi Ohno of Toyota studied Ford's original thinking in detail and invented the concepts and tools of the Toyota Production System (TPS). The main focus of TPS is cost reduction through waste elimination, which encourages using a "just in time" production system to produce only what is needed, when it is needed, in the quantity that is needed (Ohno, 1988). Later, Womack et al. (1990), in their book "The Machine that Changed the World," coined the term "lean production," which is a direct descendent of TPS. This book describes a lean system and its underlying concepts. In a subsequent book, "Lean Thinking,” Womack and Jones (1996) explored lean principles further and extended these principles to the enterprise level.

Lean is generally associated with methods for eliminating waste and improving flow. The transfer of lean principles from Japan to the U.S., however, occurred in a piecemeal and informal fashion over the course of many years. As a result, until recently we have not had a precise way of defining lean. According to Shah and Ward (2007), "Lean production is an integrated sociotechnical system whose main objective is to eliminate waste by concurrently reducing or minimizing supplier, customer, and internal variability." In short, lean focuses on eliminating waste and improving the flow of work using proven methods, and lean tools or techniques are most often applied to improve the flow of information and/or materials.

Waste found in work processes stems mainly from unnecessary delays, tasks, costs, moves, and errors. The seven wastes of lean include overproduction, transportation, inventory, processing, waiting, motion, and defects. These wastes can also be applied not only in manufacturing but also in support functions such as procurement, engineering, invoicing, inventory control, order entry, scheduling, accounting, and sales, as well as in service industries. Unfortunately, these wastes are inherent in every process and lean principles provide the underlying philosophy, tools, and techniques to reduce them. These methods range from a simple housekeeping process such as 5S to more complex kanban systems, which help to control inventory levels. Strong proof of the power of lean systems is evident through the continued success of Toyota over the past two decades. Over time lean principles have migrated throughout the entire enterprise and are now proving to be beneficial in service applications as well. As a result, the tools and principles of lean thinking have spread beyond manufacturing to service organizations such as retail, healthcare, and even government (Lean-Enterprise-Institute, 2007).

\subsection{Quality improvement}

Knowledge has historically played an essential role in the development of quality improvement methods. Specifically, Deming's (Deming, 1994) System of Profound Knowledge has four principle elements: Theory of System, Theory of Variation, Psychology, and Theory of Knowledge which describe a cooperation-based style of management that helps people simultaneously enjoy both their work and learning. Deming suggested that this approach will lead to long-term market success. Deming also advocated the use of the Plan-Do-Check-Act (PDCA) cycle (Shewhart, 1939) to solve problems. He generally referred to this process as a "learning cycle" and later modified this process to emphasize learning and reflection by changing the "check" step to "study" (Deming, 1986).

Ishikawa (1968) developed many quality improvement techniques or tools to support the principles and practices outlined by Deming and other quality leaders. These methods are often used today in business management, engineering, and technology fields and include the 7 Old Tools (i.e., basic/quality control tools) and the 7 New Tools (i.e., management and planning tools). In the 1980s, these techniques became part of the TQM approach to quality improvement. Since that time, these tools have also been incorporated into one of the most recent evolutions of the quality movement known as the Six Sigma methodology, which has been formally defined as "....an organized, parallel-meso structure to reduce variation in organizational processes by using improvement specialists, a structured method, and performance metrics with the aim of achieving strategic objectives" (Schroeder et al, 2008). In short, quality improvement methods focus on reducing defects or errors by eliminating variation in both manufacturing and service operations; hence, quality tools are often used to investigate problems and develop appropriate solutions to address these problems (Evans and Lindsay, 2005).

Unfortunately, variation is inherent in every process and quality improvement methods provide the tools necessary to reduce unwanted variation and solve problems. Techniques reducing variation include data analysis methods, idea generation, and organization tools as well as approaches for process monitoring and control (Tague, 2005). Today, organization often use approaches, which encompass these tools such as PDCA, TQM, or the Six Sigma methodology, to guide continuous improvement efforts (Pande et al, 2000; Snee and Hoerl, 2003). Confirmation of the benefits achieved as a result of using these methods is evident through the continued success of companies, such as General Electric, Caterpillar, and Bank of America, which have used these methods for some time and have reported significant financial savings as a result of Six Sigma projects (Montgomery and Woodall, 2008). 


\section{Study Methodology}

The web-based survey used to collect data for this study is shown in Figure 1. It was divided into two parts in order to improve the quality and quantity of responses. The two parts included an analysis of the use of lean techniques and the use of quality tools. The survey items which pertained to the successful implementation of lean methods were administered to members of the Institute of Industrial Engineers' Lean Division. The survey items that focused on the use of quality tools were administered to former participants in North Carolina State University’s Six Sigma program and its affiliates. A total of 187 practitioners participated in the study, resulting in a 75 percent response rate (i.e., 73 responses were collected for survey items regarding the successful implementation of lean methods and 114 responses were collected for survey items regarding the use of quality tools). Surveys with an excessive number of missing responses were removed from the study, which reduced the final sample size to 157 responses (i.e., 73 for lean methods and 84 for quality tools).

The following are examples of items included in the web-based survey administered to practitioners where ' $x$ ' represents a particular continuous improvement technique (see Table 1). Respondents were asked to indicate their level of agreement with the statements given using a five-point Likert scale. Before beginning the survey, respondents were instructed to consider the lean/quality improvement methods used within their organizations within the last three years.

\section{Part I: Lean methods}

1. My organization has successfully implemented $x$ technique.

2. Why have lean methods been successfully implemented within your organization? (Select all that apply from list provided - see Figure 4.)

3. My organization has not successfully implemented $\mathrm{x}$ technique.

4. Why have lean methods not been successfully implemented within your organization? (Select all that apply from list provided - see Figure 6.)

Part II: Quality Improvement Methods

1. My organization often uses $x$ technique.

2. When my organization used $x$ technique, we found it to be very effective.

3. Please describe the challenges faced when implementing quality improvement methods. (Open ended comment box provided.)

Figure 1. Example survey items

The sample of respondents who participated in the survey included practitioners from manufacturing and service operations in the U.S. The number of responses obtained from those working in manufacturing environments compared with service environments was relatively equal (i.e., 57 percent manufacturing operations and 43 percent service operations). The leading industries represented by survey respondents are given in Table 2 and the majority of respondents had job titles of president, vicepresident, director, manager, or engineer. Their job functions were concerned mainly with lean methods or quality practices and the majority of respondents had more than five years of experience working in these specific areas. In addition, 75 percent of respondents indicated that their organization had successfully implemented lean methods within the last three years, and 88 percent of respondents indicated that their organizations had used quality improvement methods to effectively investigate/solve problems within the last three years. Based on this information, it was concluded that respondents were qualified to provide responses to survey items examined in this study.

Table 2. Industries represented by survey respondents

\begin{tabular}{|c|c|c|}
\hline & Industry & Respondents \\
\hline \multirow{3}{*}{ 总 } & General manufacturing & $38 \%$ \\
\hline & Aerospace/automotive & $12 \%$ \\
\hline & Healthcare/medical & $11 \%$ \\
\hline \multirow{4}{*}{ 莺莺 } & Healthcare/medical & $36 \%$ \\
\hline & General manufacturing & $19 \%$ \\
\hline & Pharmaceutical/chemical & $8 \%$ \\
\hline & Plastics/injection molding & $8 \%$ \\
\hline
\end{tabular}




\section{Study Results}

The results of this research are presented in four sections, 4.1 through 4.4. The first two, sections 4.1 and 4.2, focus on the success and failure of lean techniques. The remaining two, sections 4.3 and 4.4, discuss the use and effectiveness of quality improvement methods.

\subsection{Research question 1: Successful implementation of lean methods}

This research question investigated which lean methods practitioners have implemented successfully, whether lean techniques have different success rates in manufacturing versus service environments, and what factors contribute to the successful implementation of these techniques. Figure 1 shows the percent of respondents that agreed/strongly agreed that their organization had successfully implemented a particular lean technique. It also depicts the same information for manufacturing and service operations separately. The discussion of the results presented here will first describe the lean techniques that practitioners reported successfully implementing in their organizations overall, and then it will compare the successful implementation of these techniques between manufacturing and service environments.

Overall, the technique that the largest percent (85 percent) of practitioners surveyed said their organizations successfully implemented was 5S/visual factory. Also, more than 70 percent indicated their organizations successfully implemented value stream mapping (VSM) and standardized work. In addition, approximately 50 percent or more of the respondents reported that kanban and poke-yoke were used successfully within their organizations. The techniques that the least number of practitioners said were successfully implemented within their organizations included single minute exchange of die (SMED) (38 percent) and heijunka (level out the workload) (33 percent).

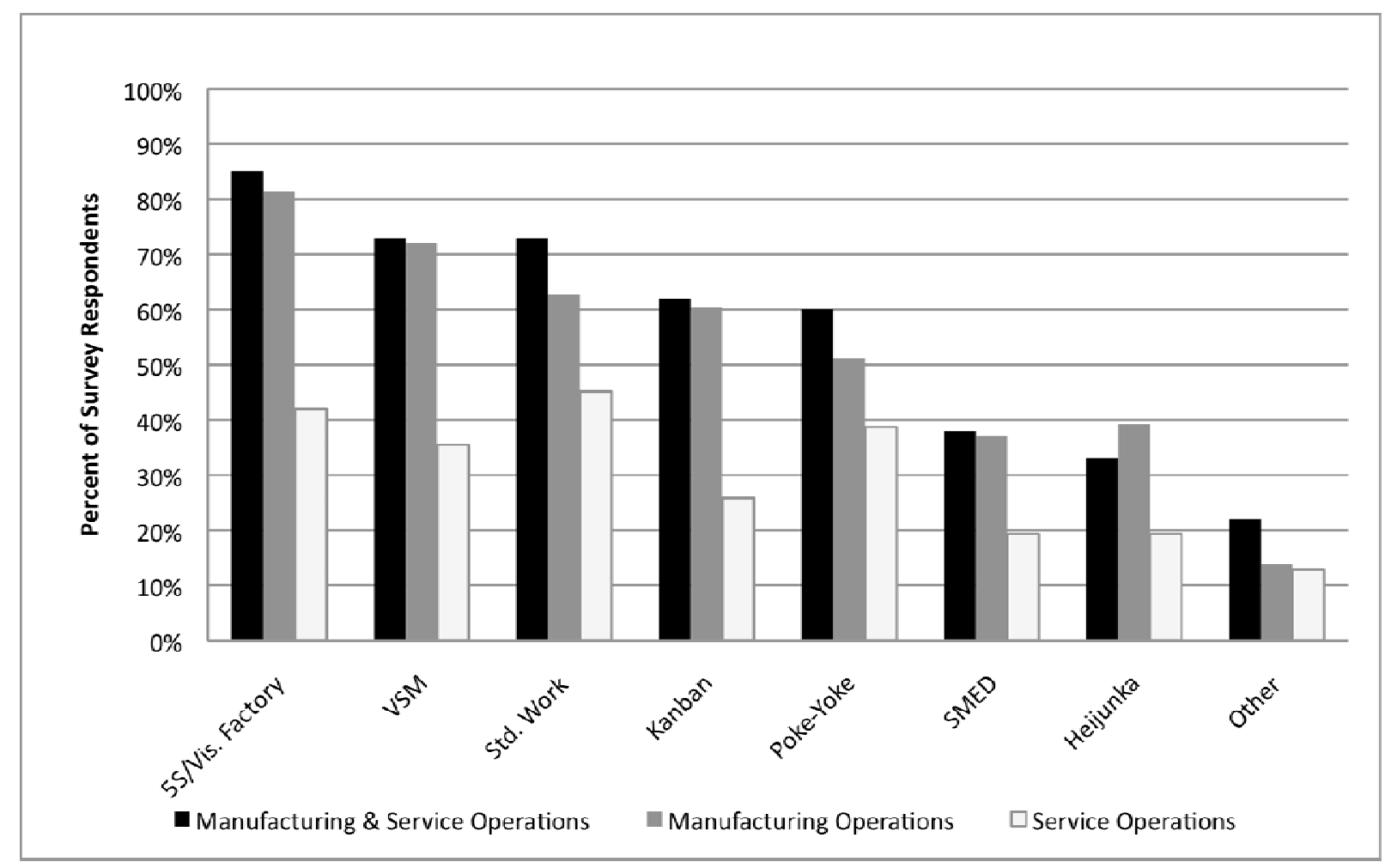

Figure 1. Successful implementation of lean techniques

Figure 1 also indicates that the trend in the successful implementation of lean techniques within manufacturing operations closely follows the results described previously; yet, approximately twice as many respondents working in manufacturing operations indicated their organizations have successfully implemented these techniques compared with service environments. Within service operations, more than 40 percent of the practitioners surveyed indicated their organizations successfully implemented 5S/visual factory and standardized work. In addition, more than 30 percent said VSM and poke-yoke were used successfully within their organizations. The techniques that the least number of service oriented practitioners indicated were successfully implemented within their organizations included kanban (26 percent), SMED (19 percent), and heijunka (19 percent). 
As part of this research, respondents were asked to identify reasons why these techniques had been successfully implemented within their organizations. As shown in Figure 2, more than 50 percent of practitioners indicated that 1) obtaining commitment from leadership, 2) documenting the financial impact/savings, and 3) expanding lean beyond manufacturing into all areas led to the successful implementation of lean techniques.

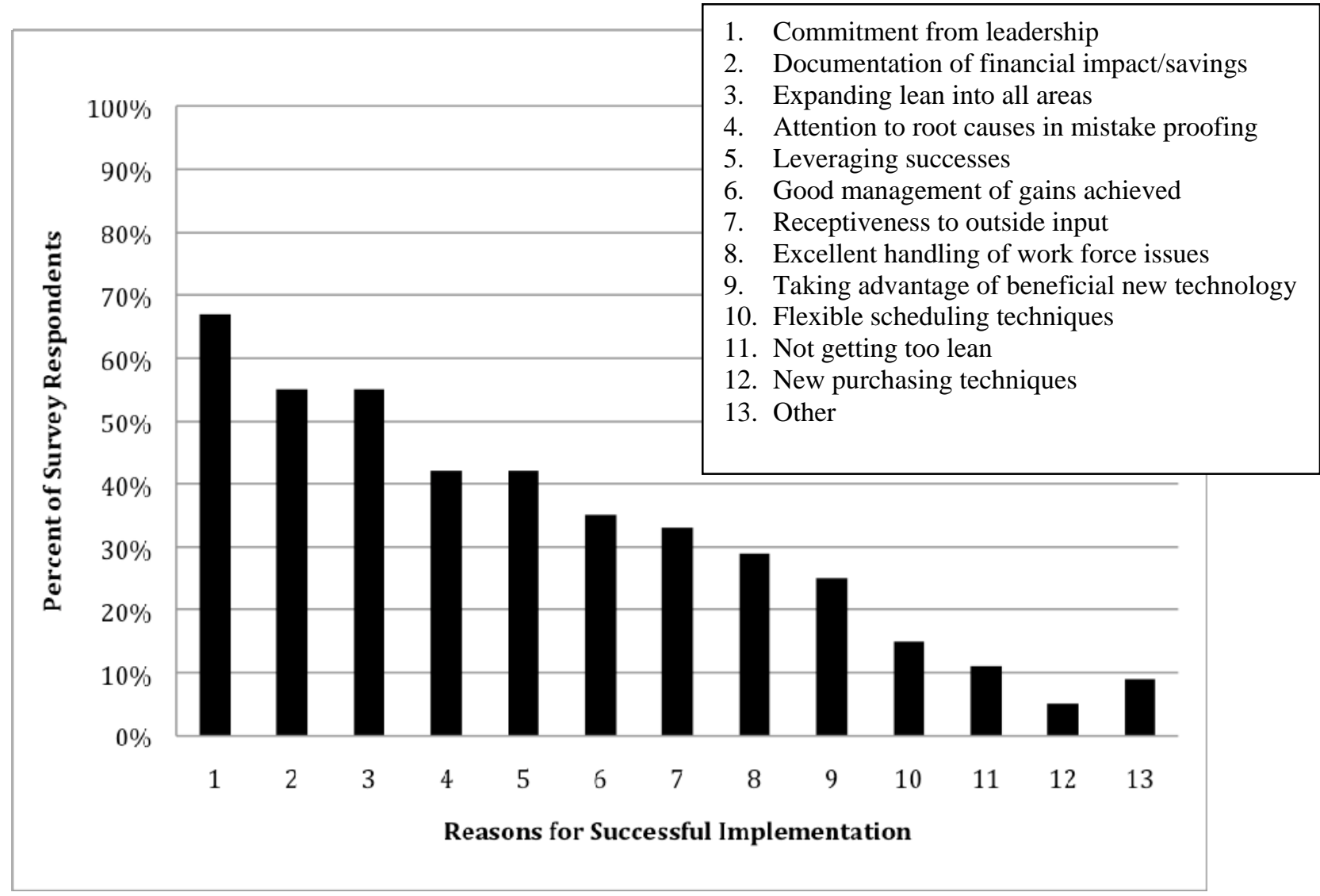

Figure 2. Reasons for successful implementation of lean techniques

\subsection{Research question 2: Failure of lean techniques}

This study also asked practitioners to identify which lean methods have been implemented unsuccessfully within their organizations and indicate the reasons why these techniques failed. As shown in Figure 3, more than 60 percent of respondents said their organizations were unsuccessful in implementing standardized work, while more than 50 percent indicated that VSM was also implemented unsuccessfully. In addition, just over 40 percent of survey respondents said that 5S/visual factory, pokeyoke, and kanban were implemented unsuccessfully within their organizations. 


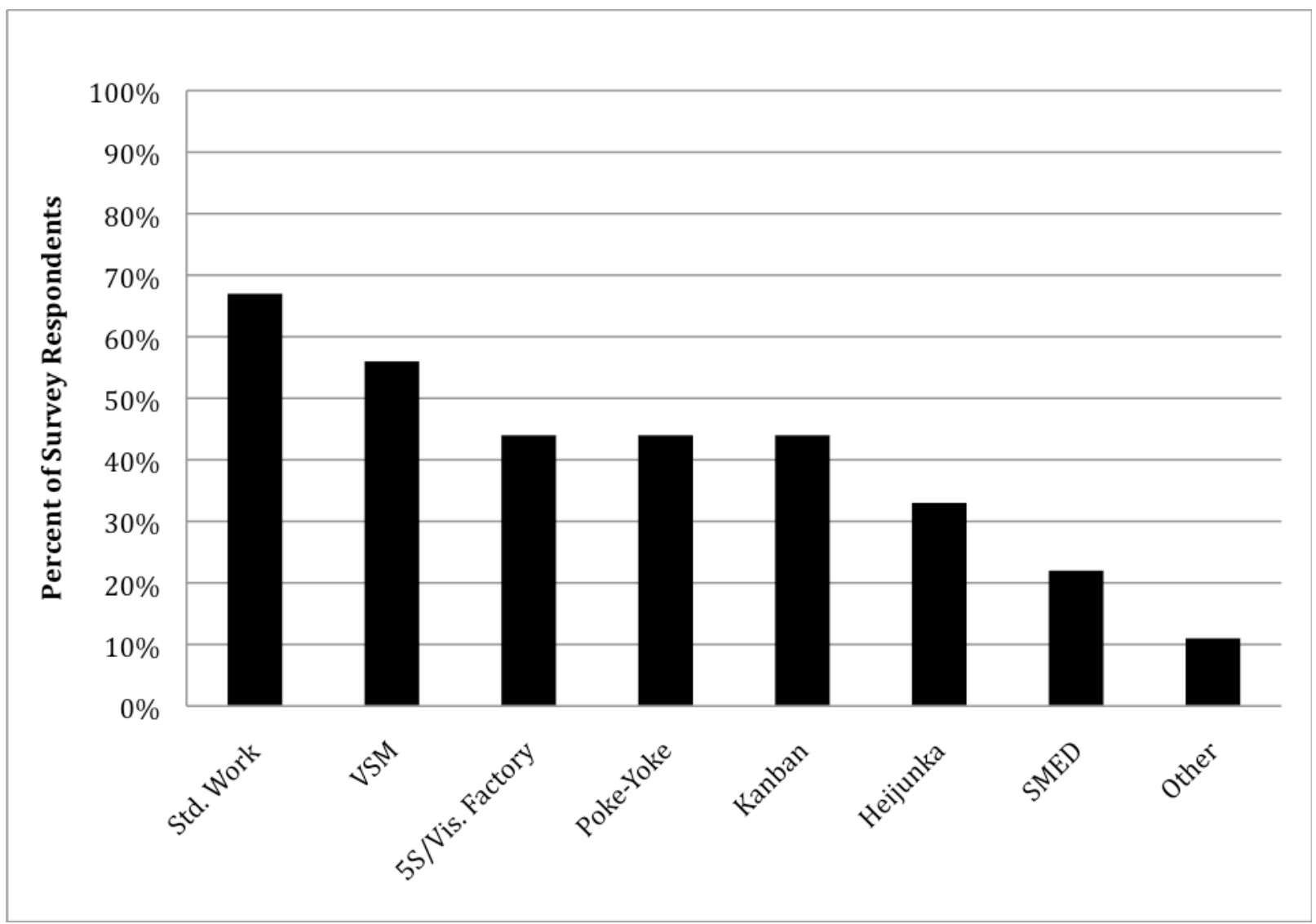

Figure 3. Failed implementation of lean techniques

The top reasons cited by survey respondents to explain the unsuccessful implementation of lean techniques, which are depicted in Figure 4, involved 1) lack of commitment from leadership (88 percent), 2) not really mistake proofing the root cause of the mistakes (75 percent), 3) failure to address work force issues (50 percent), and 4) failing to hold the gains (50 percent). Several respondents also volunteered additional comments that provide further insight regarding the reasons for the failure in implementing lean techniques. These comments included:

- Leadership commitment is non-existent

- "It’s not my job” thinking

- Lack of understanding by management

- Improvement driven by edict - overworking line management

\subsection{Research question 3: Effectiveness of quality improvement methods}

This research question examined the perceived effectiveness of quality improvement methods, including which tools practitioners reported using in their organizations to solve problems and whether the effectiveness of these tools differs between types of operations (i.e., manufacturing versus service). Figure 5 shows the percent of respondents that agreed/strongly agreed that when their organization used the tool indicated, they found it to be very effective in terms of investigating/solving problems. This figure also depicts, separately, the same results for manufacturing and service operations. The following discussion will first describe the results obtained regarding the effectiveness of quality improvement methods that practitioners reported using in their organizations. It will then compare the reported effectiveness of these methods between manufacturing and service environments.

Overall, it is interesting to note that a larger percent of respondents indicated that the 7 Old Tools were effective in terms of investigating/solving problems within their organizations compared with that reported for the 7 New Tools. Specifically, the quality tool that the largest percent (88 percent) of practitioners felt is effective was flowcharts. Also, more than 70 percent indicated said that histograms, control charts, and Pareto charts were effective when used within their organizations. The tools that the least number of practitioners said were effective included interrelationship diagraphs (IDs) (18 percent), process decision program charts (PDPCs) (16 percent), and activity network diagrams (ANDs) (9 percent), which are three of the 7 New Tools. 


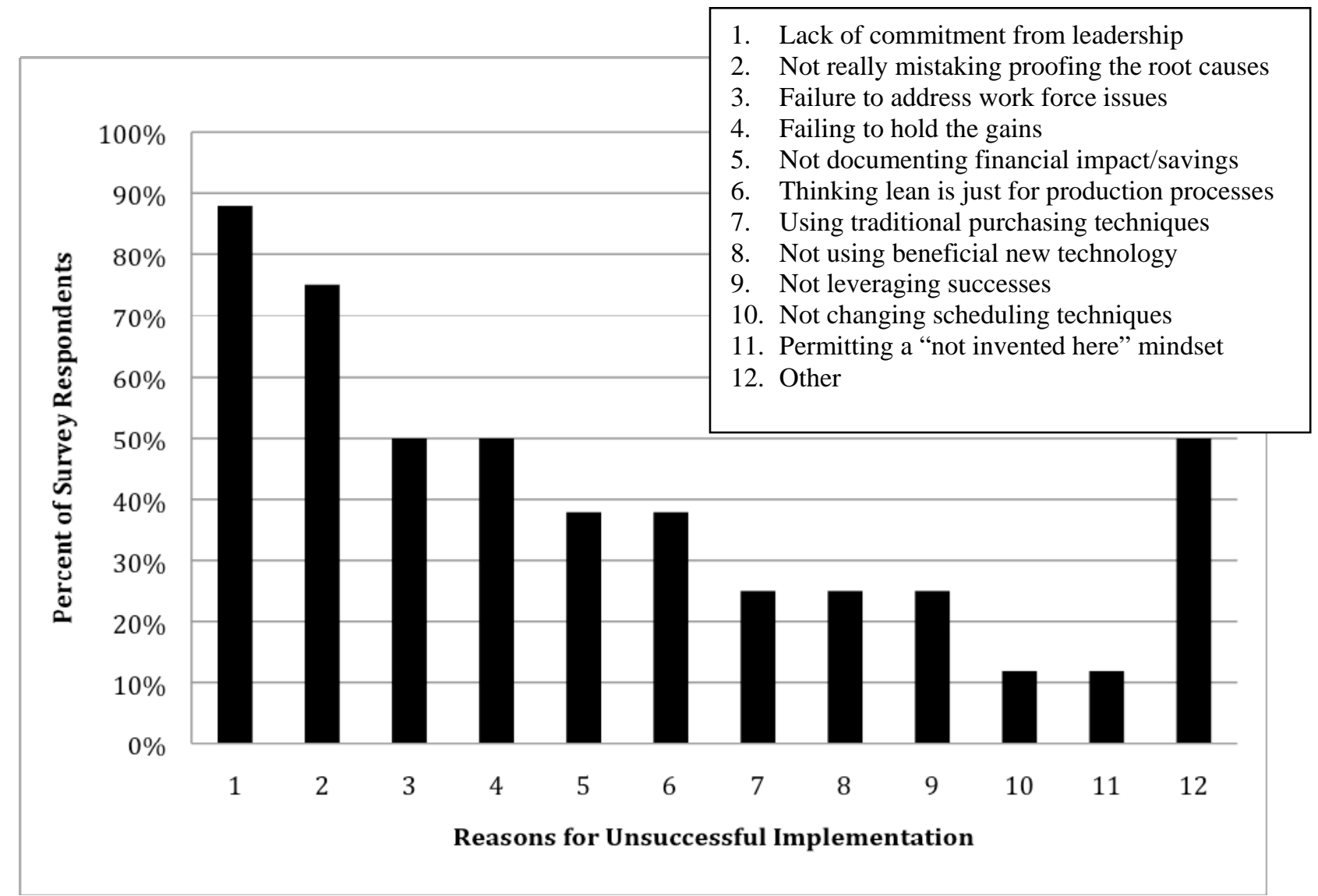

Figure 4. Reasons for the failed implementation of lean techniques

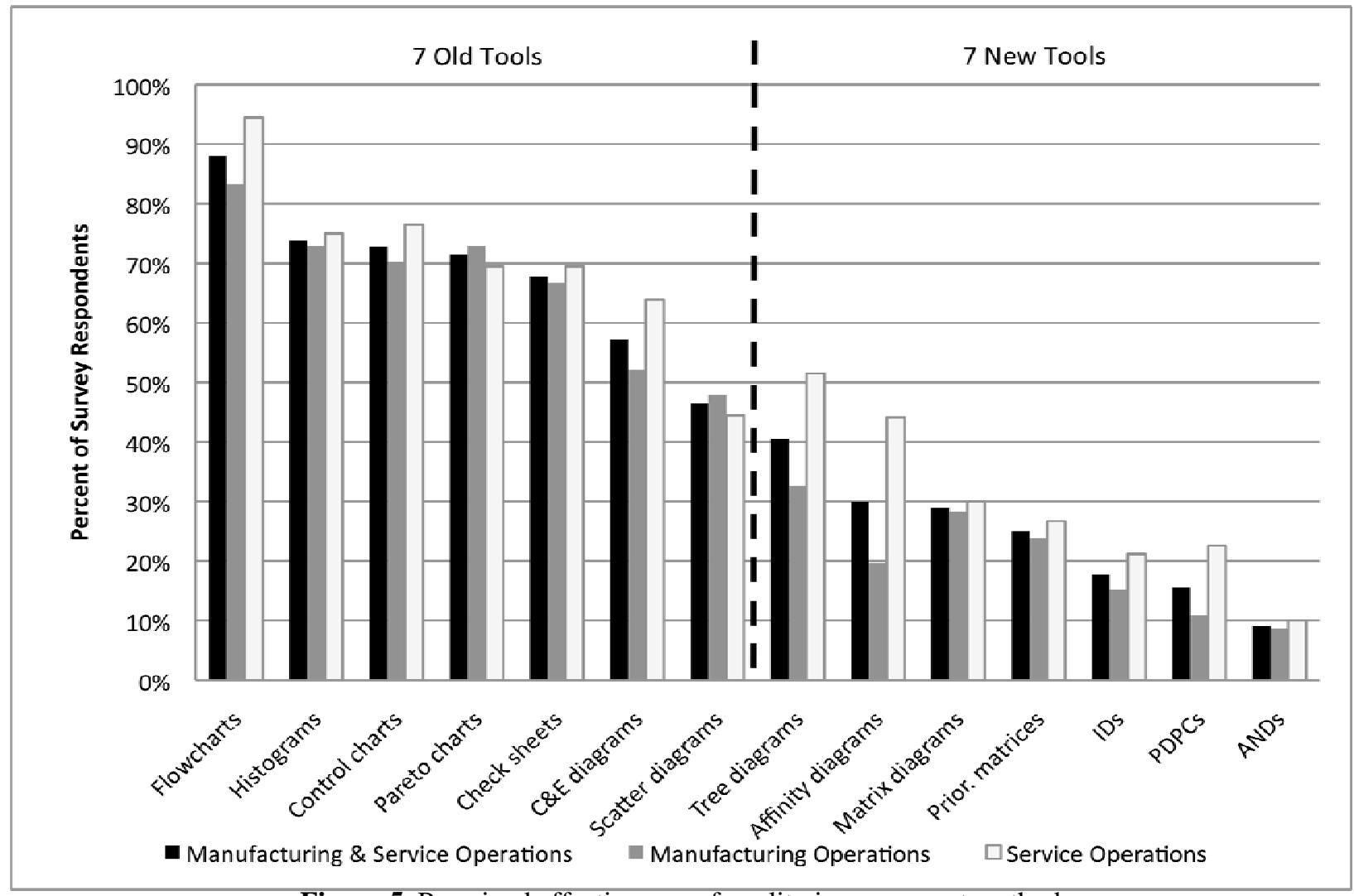

Figure 5. Perceived effectiveness of quality improvement methods 
Furthermore, Figure 5 indicates that, regardless of the environment in which they work (i.e., both manufacturing and service operations), a larger percent of practitioners reported that the 7 Old Tools were effective in terms of investigating/solving problems within their organizations compared with the $7 \mathrm{New}$ Tools. In addition, more practitioners from service operations tended to indicate that quality improvement methods were effective than those from manufacturing environments, especially for the several of the 7 New Tools including tree diagrams, affinity diagrams, and PDPCs.

\subsection{Research question 4: Challenges faced when implementing quality improvement methods}

The challenges faced in implementing quality improvement methods reported by survey respondents included both high and low level organizational factors. The high level issues that respondents shared involved the support of top management and the motivation and commitment of the work force. They indicated that without full support from management, it was difficult to get other employees involved in improvement initiatives, including the use of quality tools to investigate/solve problems. Other issues cited by participating quality practitioners included some of the more practical constraints they face, such as the lack of appropriate resources to support improvement efforts (i.e., insufficient training, budgets, and time to conduct quality improvement projects) as well as unrealistic timeframes to investigate/solve problems (i.e., a problem that might take six months to solve might be expected to be completed in just two months).

\section{Discussion}

This research examined the implementation and effectiveness of continuous improvement methods that practitioners in the U.S. use to improve productivity and solve problems. In terms of lean techniques, the majority of practitioners surveyed indicated that 5S/visual factory, VSM, standardized work, kanban, and poke-yoke were among the lean techniques their organizations had successfully implemented. It is likely that $5 \mathrm{~S} /$ visual factory was often reported as being successfully implemented due to its relatively simple methods and low cost. Since 5S in its simplest form involves keeping workplaces well organized and clean, it involves few changes to the manufacturing process; thus, it requires minimal resources (i.e., time, material, etc.) for implementation (Hirano, 1996). Also, VSM is one of the most fundamental lean practices, and although this technique can be very involved, it is often a first step in estimating how much waste exists in a process so that projected savings from a lean program can be estimated (Cudney, 2009). In addition, since standardized work is already in place to some extent in many work environments, it may not require significant changes. Therefore, it may be relatively easy to implement this technique in many settings by simply documenting existing processes. Few practitioners, however, reported that their organizations had successfully implemented techniques such as SMED and heijunka, which are more complex lean methods that require greater organizational change to implement (Cudney, 2009).

For many lean techniques, approximately twice as many respondents working in manufacturing operations reported successful implementation compared with service environments. This is understandable because the lean philosophy began with the Toyota Production System; therefore, the use of lean methods within manufacturing operations is better developed and there are more examples available to support improvement efforts. Unfortunately, the use of lean techniques within service environments is less mature partly because it is much harder to measure success in the face of high degree of customer contacts and low skill level of the service employees. Service operations may be able to successfully implement methods such as standardized work and $5 \mathrm{~S} /$ visual factory because they are inexpensive and easy to implement, as discussed previously; yet, these organizations are probably less likely to report successfully implementing techniques such as kanban, SMED, and heijunka because they are relatively difficult to implement that may not be applicable to the work done in service operations.

In terms of quality improvement methods, the majority of practitioners surveyed reported that five of the 7 Old Tools, including flowcharts, check sheets, histograms, Pareto charts, and control charts, were effective in terms of investigating/solving problems within their organizations. In addition, a larger percent of practitioners working in service environments indicated that quality improvement methods were more effective than those from manufacturing environments, especially for the several of the $7 \mathrm{New}$ Tools. Typically, what is studied and measured in service oriented improvement projects is often much different from that considered in a manufacturing oriented project (Does et al, 2002; Antony, 2007); hence, practitioners should consider whether a particular tool will be helpful in the process of investigating/solving, because different tools are useful in different contexts (Cudney, 2009).

It was also found that larger percent of practitioners generally reported that that the 7 Old Tools were effective in terms of investigating/solving problems within their organizations as compared with that reported for the 7 New Tools, regardless of the whether they work in manufacturing or service operations. Previously, a study by Evans (1996) of Malcolm Baldrige National Quality Award winners found that the importance of knowing the 7 Old Tools was ranked much higher among these organizations as compared with the importance of knowing the 7 New Tools. This research also found that training for line managers, technical staff, and frontline employees within Baldrige recipient organizations focused to a larger extent on teaching the 7 Old tools versus the 7 New tools. An additional study by Weinstein et al. (1998) indicates that quality courses offered within community colleges, undergraduate programs, and graduate programs also tend to focus on teaching the 7 Old Tools more than the 7 New Tools. As shown in Table 3, this is also the case for the instructional materials used by North Carolina State University's Six Sigma Green Belt level training program, which most survey respondents participated in. Therefore, it is likely that most survey respondents 
received more instruction in how to use the 7 Old Tools compared with the 7 New Tools, which may explain the differences in use and perceived effectiveness.

Table 3. Quality improvement methods taught in Green Belt level Six Sigma training

\begin{tabular}{|l|ll|l|l|}
\hline Included & 7 Old Tools & Included & 7 New Tools \\
\hline$\sqrt{ }$ & 1. & Flowcharts & $\sqrt{ }$ & 1. Affinity Diagrams \\
\hline & 2. Check Sheets & & 2. Interrelationship Diagraphs (IDs) \\
\hline$\sqrt{ }$ & 3. & Histograms & $\sqrt{ }$ & 3. Tree Diagrams \\
\hline$\sqrt{ }$ & 4. Pareto Charts & & 4. Process Decision Program Charts (PDPCs) \\
\hline$\sqrt{ }$ & $5 . \quad$ Cause and Effect Diagrams & & 5. Matrix Diagrams \\
\hline$\sqrt{ }$ & 6. Scatter Diagrams & & 6. Prioritization Matrices \\
\hline$\sqrt{ }$ & $7 . \quad$ Control Charts & & 7. Activity Network Diagrams (ANDs) \\
\hline
\end{tabular}

Finally, there were many similarities between the reasons given by practitioners regarding why the use of continuous improvement techniques are not successful or are not perceived as effective within their organizations. The reasons given that tended to overlap between lean and quality techniques included the lack of support of top management and poor motivation and commitment of the work force. These results reinforce what has been discussed previously in the literature regarding various factors that have a direct effect on the success of lean and quality improvement initiatives, which many quality managers recognize as enduring problems (Jacobsen, 2008; Swayne and Harder, 2003; Sandholm and Sorqvist, 2002; Chakravorty, 2010).

\section{Summary}

The results of this study suggest that some continuous improvement methods are more often successfully implemented and perceived to be effective than others. These findings provide useful information for practitioners seeking ways to improve their organizational performance by suggesting a starting point for deploying lean and/or quality improvement methods. Furthermore, the methods identified as not successfully implemented or not perceived as effective suggest areas that employee training and/or academic programs might focus to increase the use of these techniques. In addition, by examining survey results by the type of operation, this work provides others working in similar environments with suggestions about what tools might work well for them; yet, further research is needed to develop a better understanding about how additional techniques can be applied effectively within various types of operations. Yet, these findings raise the question "Do practitioners use improvement methods because they perceive that the tools are effective?” or "Do practitioners think the tools are effective because they use them?” An answer to this question cannot be concluded from the present study, but this issue may be a good subject for future research in this field.

Finally, the common themes that emerged from the investigation regarding the challenges/reasons for failure associated with continuous improvement techniques provide support for previous discussions in the literature. Previous studies have also found evidence that suggests the use and effectiveness of different tools varies between applications in different environments, as well as how various organizational factors, which are often hard to control, have a direct effect on the success of these initiatives. This study, therefore, further emphasizes that these are enduring problems, which practitioners should be aware of and future investigations should try to resolve.

\section{References}

Alavi, M. and Leidner, D. E. (2001) 'Knowledge management and knowledge management systems: Conceptual foundations and research issues', MIS Quarterly, Vol. 25, No. 1, pp. 107-136.

Antony, J., et al. (2007) Six sigma in service organisations: Benefits, challenges and difficulties, common myths, empirical observations and success factors. International Journal of Quality \& Reliability Management, 24(3): p. 294-311.

Chakravorty, S. S. (2010) 'Where process-improvement projects go wrong', Wall Street Journal, January 25, 2010.

Choo, A. S., Linderman, K. W. and Schroeder, R. G. (2007) 'Method and psychological effects on learning behaviors and knowledge creation in quality improvement projects', Management Science, Vol. 53, No. 3, pp. 437.

Cudney, E. (2009) Using Hoshin Kanri to Improve the Value Stream. New York: Productivity Press.

Curkovic, S., Vickery, S. and Droge, C. (2000) 'Quality-related action programs: Their impact on quality performance and firm performance', Decision Sciences, Vol. 31, No. 4, pp. 885-905.

Davenport, T. H. and Prusak, L. (1998) Working knowledge: How organizations manage what they know Boston, MA: Harvard Business School Press.

Dean, J. W. and Bowen, D. E. (1994) 'Management theory and total quality: Improving research and practice through theory development', Academy of Management Review, Vol. 19, No. 3, pp. 392-418.

Deming, W. E. (1986) Out of the crisis, Cambridge, MA: MIT Press.

Deming, W. E. (1994) The new economics: For industry, government, education, Cambridge, MA: MIT Press. 
Does, R., et al. (2002) Comparing Nonmanufacturing with Traditional Applications of Six Sigma. Quality Engineering, 15(1): p. 177-182.

Douglas, T. and Fredendall, L. (2004) 'Evaluating the deming management model of total quality in services', Decision Sciences, Vol. 35, No. 3, pp. 393-422.

Drucker, P. F. (1993) Post-capitalist society, NY: HarperBusiness.

Evans, J. (1996) What should higher education be teaching about quality? Quality Progress. 29(8): p. 83-89.

Evans, J. R. and Lindsay, W. M. (2005) The management and control of quality, Cincinnati, Ohio: South-Western College Publishing.

Flynn, B., Schroeder, R. and Flynn, E. (1999) 'World class manufacturing: An investigation of hayes and wheelwright's foundation', Journal of Operations Management, Vol. 17, No. 3, pp. 249-269.

Gitlow, H., A. Oppenheim, and R. Oppenheim (1995) Quality Management: Tools and Methods for Improvement. 2nd ed., Burr Ridge, IL: Irwin.

Grant, R. M. (1996) 'Toward a knowledge-based theory of the firm', Strategic Management Journal, Vol. 17, No. 10, pp. 109-22.

Grant, R. M. (1997) 'The knowledge-based view of the firm: Implications for management practice', Long range planning, Vol. 30, No. 3, pp. 450-454.

Hackman, J. R. and Wageman, R. (1995) 'Total quality management: Empirical, conceptual, and practical issues', Administrative Science Quarterly, Vol. 40, No. 2, pp. 309-42.

Hirano, H. (1996) 5 S for operators: 5 pillars of the visual workplace. New York: Productivity Press.

Ishikawa, K. (1968) Guide to quality control, White Plains, NY: Quality Resources.

Ishikawa, K. (1985) What is total quality control? The japanese way, Englewood Cliffs, NJ: Prentice-Hall.

Jacobsen, J. (2008) 'Avoiding mistakes of the past: Lessons learned on what makes or breaks quality initiatives', The Journal for Quality and Participation, Vol. 31, No. 2, pp. 4-9.

Juran, J. M. (1969) Managerial breakthrough: A new concept of the managers job, New York: McGraw-Hill.

Juran, J.M., (1974) Quality Control Handbook. 3 ed., New York: McGraw Hill.

Kogut, B. and Zander, U. (1992) 'Knowledge of the firm, combinative capabilities, and the replication of technology', Organization Science, Vol. 3, No. 3, pp. 383-397.

Kovach, J., De la Torre, L. and Walker, D. (2008) 'Continuous improvement efforts in healthcare: A case study exploring the motivation, involvement and support necessary for success', International Journal of Six Sigma and Competitive Advantage, Vol. 4, No. 3, pp. 254-269.

Lapré, M. A., Mukherjee, A. S. and Van Wassenhove, L. N. (2000) 'Behind the learning curve: Linking learning activities to waste reduction', Management Science, Vol. 46, No. 5, pp. 597-611.

Lean Enterprise Institute (2007) 'A brief history of lean', Available online at: http://www.lean.org/WhatsLean/History.cfm (accessed 19 December 2009).

Manos, A., Sattler, M. and Alukal, G. (2006) 'Make healthcare lean', Quality Progress, Vol. 39, No. 7, pp. 24-30.

Montgomery, D.C. and W.H. Woodall (2008)) An overview of six sigma. International Statistical Review, 76(3): p. 329-346.

Mukherjee, A. S., Lapre, M. A. and van Wassenhove, L. N. (1998) 'Knowledge driven quality improvement', Management Science, Vol. 44, No. 11, pp. 35-49.

Nonaka, I. (1994) 'A dynamic theory of organizational knowledge creation', Organization Science, Vol. 5, No. 1, pp. 14-37.

Ohno, T. (1988) Toyota production system: Beyond large-scale production, Cambridge, MA: Productivity Press.

Pande, P. S., Neumann, R. P. and Cavanagh, R. R. (2000) The six sigma way: How GE, Motorola, and other top companies are honing their performance: McGraw-Hill.

Peteraf, M. A. (1993) 'The cornerstones of competitive advantage: A resource-based view', Strategic Management Journal, Vol. 14, No. 3, pp. 179-191.

Sabherwal, R. and Becerra-Fernandez, I. (2003) 'An empirical study of the effect of knowledge management processes at individual, group, and organizational levels', Decision Sciences, Vol. 34, No. 2, pp. 225-260.

Sandholm, L. and Sorqvist, L. (2002) '12 requirements for six sigma success', Six Sigma Forum Magazine, Vol. 2, No. 1, pp. 1722.

Schroeder, R. G., Linderman, K., Liedtke, C. and Choo, A. S. (2007) 'Six sigma: Definition and underlying theory', Journal of Operations Management, Vol. In Press, No.

Senge, P. (1992) 'Building learning organizations', Journal for Quality and Participation, Vol. 15, No. 2, pp. 30-38.

Shah, R. and Ward, P. T. (2007) 'Defining and developing measures of lean production', Journal of Operations Management, Vol. 25, No. 4, pp. 785-805.

Shewhart, W. A. (1939) Statistical method from the viewpoint of quality control, New York: Reprint, 1986, with introduction by W. Edwards Deming. Dover Publications.

Sitkin, S. B., Sutcliffe, K. M. and Schroeder, R. G. (1994) 'Distinguishing control from learning in total quality management: A contingency perspective', The Academy of Management Review, Vol. 19, No. 3, pp. 537-564.

Snee, R. D. and Hoerl, R. W. (2003) Leading six sigma: A step-by-step guide based on experience with GE and other six sigma companies, Upper Saddle River, NJ: Prentice Hall, Financial Times. 
Swayne, B. and Harder, B. (2003) 'Where has all the magic gone?', Six Sigma Forum Magazine, Vol. 2, No. 3, pp. $22-27$. Tague, N. R. (2005) The quality toolbox, Milwaukee, WI: ASQ Quality Press.

Vera, D. and Crossan, M. (2003). Organizational learning and knowledge management: Toward an integrative framework. Handbook of organizational learning and knowledge management. M. Easterby-Smith and Lyles, A. Malden, MA, Blackwell: 122-141.

Weinstein, L., et al. (1998) What higher education should be teaching about quality—but is not. Quality Progress, Vol. 31, No. 4, pp. 91-95.

Wernerfelt, B. (1984) 'A resource-based view of the firm', Strategic Management Journal, Vol. 5, No. 2, pp. 171-180.

Womack, J. and Jones, D. (1996) Lean thinking: Banish waste and create wealth in your organisation, New York: Rawson Associates.

Womack, J. P., Jones, D. T. and Roos, D. (1990) The machine that changed the world, New York: Rawson Associates.

\section{Biographical notes}

Dr. Jamison V. Kovach is an Assistant Professor in the Department of Information and Logistics Technology at the University of Houston. She received her Ph.D. in Industrial Engineering from Clemson University. Her industrial experience includes several years as a product and process improvement engineer in the U.S. textile industry. Her responsibilities included working within both ISO 9000 and QS 9000 quality management systems and improving the shade quality of apparel and automotive dyed fabrics. Currently, her research interests include robust design, experimental design, and the application of quality improvement and management methods for organizational problem solving. She is certified in Six Sigma Black Belt training and is the Director of the Six Sigma program at the University of Houston. Through this program, she instructs students and industrial clients on the use of Six Sigma and other quality improvement initiatives within their organizations. Her research has been published in Engineering Optimization, Quality Engineering, and International Journal of Quality and Reliability Management journals, and she is a member of ASQ, IIE, DSI, PMI, and POMS. She is the recipient of the ASQ 2010 Feigenbaum Medal.

Dr. Elizabeth Cudney is an Assistant Professor at Missouri University of Science and Technology. She received her B.S. in Industrial Engineering from North Carolina State University, Master of Engineering in Mechanical Engineering and Master of Business Administration from the University of Hartford, and her doctorate in Engineering Management from the University of Missouri - Rolla. In 2010, Dr. Cudney was inducted into the ASQ International Academy for Quality. She received the 2008 ASQ A.V. Feigenbaum Medal and the 2006 SME Outstanding Young Manufacturing Engineering Award. She is an ASQ Certified Quality Engineer, Manager of Quality/Operational Excellence, and Certified Six Sigma Black Belt. She is a member of the ASEE, ASEM, ASME, ASQ, IIE, SAE, and the Japan Quality Engineering Society (JQES).

Dr. C.C. Elrod is an Assistant Professor in the Department of Business and Information Technology at the Missouri University of Science and Technology. She received her B.S., M.S., and Ph.D. in Engineering Management from the University of Misosuri - Rolla. Her research has been accepted and published in journals such as the Quality Management Journal and International Journal of Quality and Reliability Management. Her current area of research includes continuous improvement, supply chain management, and project management. She is a member of the American Society of Quality.

Received January 2011

Accepted June 2011

Final acceptance in revised form June 2011 